\title{
BMJ Open What do European women know about their female cancer risks and cancer screening? A cross-sectional online intervention survey in five European countries
}

Odette Wegwarth, ${ }^{1,2}$ Martin Widschwendter, ${ }^{3}$ David Cibula, ${ }^{4}$ Karin Sundström, ${ }^{5,6}$ Rosalba Portuesi, ${ }^{7,8}$ Ines Lein, ${ }^{2}$ Felix G Rebitschek, ${ }^{2}$ on behalf of the FORECEE (4C) consortium

To cite: Wegwarth 0 , Widschwendter M, Cibula D, et al. What do European women know about their female cancer risks and cancer screening? A cross-sectional online intervention survey in five European countries. BMJ Open 2018;8:e23789. doi:10.1136/ bmjopen-2018-023789

- Prepublication history and additional material for this paper are available online. To view these files, please visit the journal online (http://dx.doi. org/10.1136/bmjopen-2018023789).

Received 24 April 2018

Revised 29 July 2018

Accepted 31 October 2018

Check for updates

(C) Author(s) (or their employer(s)) 2018. Re-use permitted under CC BY-NC. No commercial re-use. See rights and permissions. Published by BMJ.

For numbered affiliations see end of article.

Correspondence to

Dr Odette Wegwarth;

wegwarth@mpib-berlin.mpg.de

\section{ABSTRACT}

Objectives Informed decisions about cancer screening require accurate knowledge regarding cancer risks and screening. This study investigates: (1) European women's knowledge of their risk of developing breast, ovarian, cervical or endometrial cancer, (2) their knowledge about mammography screening and (3) whether an evidencebased leaflet improves their knowledge.

Design Cross-sectional online intervention survey. Setting National samples from five European countries (Czech Republic, Germany, UK, Italy and Sweden)drawn from the Harris Interactive and the Toluna panel, respectively, in January 2017-were queried on their knowledge of age-specific risks of developing breast, cervical, ovarian or endometrial cancer within the next 10 years and of mammography screening before and after intervention.

Participants of 3629 women (inclusion criteria: age 4075 years) invited, 2092 responded and 1675 completed the survey (response rate: $61.4 \%$ ).

Intervention Evidence-based leaflet summarising information on age-adjusted female cancer risks, mammography and aspects of cancer prevention.

Primary outcome measures Proportion of women (1) accurately estimating their risk of four female cancers, (2) holding correct assumptions of mammography screening and (3) changing their estimations and assumptions after exposure to leaflet.

Findings Across countries, $59.2 \%(95 \% \mathrm{Cl} 56.8 \%$ to $61.6 \%$ ) to $91.8 \%$ (95\% Cl $90.3 \%$ to $93.0 \%$ ) overestimated their female cancer risks 7-33 fold (medians acrosstumours: 50.0 to 200.0 ). $26.5 \%$ (95\% Cl $24.4 \%$ to $28.7 \%$ ) were aware that mammography screening has both benefits and harms. Women who accurately estimated their breast cancer risk were less likely to believe that mammography prevents cancer $(p<0.001)$. After leaflet intervention, knowledge of cancer risks improved by $27.0(95 \% \mathrm{Cl} 24.9$ to 29.2$)$ to 37.1 (95\% Cl 34.8 to 39.4 ) percentage points and of mammography by 23.0 (95\% Cl 21.0 to 25.1$)$ percentage points.

Conclusion A considerable number of women in five European countries may not possess the prerequisites for
Strengths and limitations of this study

- Our study is, to the best of our knowledge, the first systematic investigation in five European countries of women's estimates of their age-specific risk for breast, ovarian, cervical and endometrial cancer; their basic understanding of mammography screening; the link between their cancer risk perception and their understanding of screening; and the extent to which their knowledge would benefit from the provision of evidence-based health information.

- Due to the cross-sectional design of the study, we were unable to assess whether the improved outcomes after intervention translated into any behavioural changes or were maintained over the longer run.

- We also cannot exclude the likelihood that women with a greater interest in the topic of cancer and screening were more likely to respond to our survey, which might have influenced our results and limit generalisability.

an informed choice on cancer screening. Evidence-based information in patient leaflets can improve this situation.

\section{INTRODUCTION}

Women in countries with modern healthcare systems are confronted with the question of whether to participate in screening for female cancers (ie, breast cancer, cervical cancer, ovarian cancer and endometrial cancer). Cancer screening can produce benefits by identifying treatable cancer at an early stage and thereby reducing the risk of mortality. Cancer screening can, however, also produce harms by overdiagnosis and overtreatment. ${ }^{12}$ Overdiagnosis is the detection of histopathological abnormalities that meet the definition of (pre-)cancer but would never progress to 
an invasive cancer that causes cancer-specific symptoms or death. ${ }^{23}$ The consequence of overdiagnosis is overtreatment, that is, unnecessary surgery, chemotherapy or radiation that does not benefit the patient but only harms. The proportion of benefits and harms varies by the basic risk of cancer type and screening programme ${ }^{4-8}$; thus, this information needs to be made available to the public to allow informed decisions. ${ }^{9}{ }^{10}$ Efforts to increase mortality benefits and reduce the extent of overdiagnosis by stratifying cancer screening according to risks are now underway and make the need for communicating the basic cancer risks even more apparent. ${ }^{11}$

To date, screening for endometrial cancer is neither encouraged nor recommended by any European country because evidence endorsing the screening is lacking. Likewise, population-based ovarian cancer screening using ultrasound is not recommended because current evidence demonstrates an unfavourable balance of its benefits and harms. ${ }^{412}$ New strategies assigning women to multimodal screening using blood-based tumourmarker dynamical changes ${ }^{12}$ might prove to be potentially (cost-)effective in the future and become a feasible screening tool for this type of cancer. ${ }^{13}$ In contrast, nearly all European countries have established population-based screening programmes for breast and cervical cancer on the basis of evidence demonstrating that the benefit-harm ratio is sufficiently balanced for certain age groups. ${ }^{714}$ Particularly for mammography screening, European women between 50 and 69 years receive regularly invitation letters for participating in the screening and informational material about the effectiveness of the screening.

But are women sufficiently informed about the their baseline cancer risk and the benefits and harms of mammography screening, which is a prerequisite to making an informed choice on screening attendance? In nine European countries, $92 \%$ of the women overestimated the benefit of mammography by at least an order of magnitude, and less than $10 \%$ of a national US sample regularly attending one or more cancer screenings had ever heard of overdiagnosis due to screening. ${ }^{15} 16$ The European study additionally revealed that the nature of health information provided largely influenced overestimation. Moreover, as a German national study documented, a considerable number of women incorrectly assumed that mammography screening prevents incidence of cancer. ${ }^{17}$ What remains unaddressed in these studies is whether these women had already greatly overestimated their risk of developing cancer at a certain time in life. Misperceiving one's own risk of developing cancer as being particularly high may trigger unreasonable assumptions about cancer screening. ${ }^{1517}$

This study addresses five main questions: (1) do European women know their risk of being diagnosed with breast, ovarian, cervical or endometrial cancer?; (2) do European women know that cancer screening such as mammography has both benefit and harms and does this knowledge correspond with their knowledge of their breast cancer risk?; (3) are European women in the core age group of breast cancer screening more likely to have more accurate knowledge regarding breast cancer risks and mammography screening?; (4) does an information leaflet improve European women's knowledge regarding cancer risk and screening?; and (5) do women from different European countries vary in their knowledge before and after the intervention?

\section{METHOD}

The core objectives of this study were triggered by the requirements of the ongoing Female cancer prediction using cervical omics to individualise screening and prevention (FORECEE) project- funded by the European Union's Horizon 2020 research and innovation programme-that aims to develop an epigenetic test to predict the risk for breast, ovarian, cervical and endometrial cancers in women using cervical cells (https:// forecee.eu). Part of the FORECEE project is to understand educational and communicative needs from the side of women who might be targeted by the potential introduction of the resulting women's cancer risks identification (WID) test in the future. The study reported herein investigated the educational aspect in that it sought to learn: (1) about women's knowledge of their female cancer risks and cancer screening at base line and (2) about the effect of an evidence-based leaflet (intervention) on that knowledge. To gain these insights with sufficiently large national samples from different European countries, the study was set up as a cross-sectional online survey with two phases (before/after intervention). The content of the cross-sectional online intervention survey and an evidence-based leaflet (intervention) were developed by the authors of the study; revised by clinical, epidemiological and decision analysis experts of the FORECEE consortium; and programmed by the market research institute Harris Interactive (Germany). Study materials were translated into country-specific languages by a professional translation office and checked for correctness and completeness by country-specific members of the FORECEE consortium.

\section{Sample frame}

The sample frame was the Harris Interactive Panel and the Toluna Panel, maintained and subcontracted, respectively, by Harris Interactive, an established market research institute operating in more than 60 countries worldwide. The panels are representative of the general population with respect to age, education, gender and regions in each of the countries and comprise about 78000 and 275000 female participants of the age group targeted in this study, respectively. Participants have agreed in advance to participate in online research.

\section{Sample selection}

The survey questions targeted knowledge on cancer screening and female cancer risks in European women. 
Thus, the goal was to survey national samples of women in and around the core age group of screening programmes (40-75 years) in five European countries that represent Northern, Eastern, Southern, Western and Central Europe and the nationalities of members of the FORECEE consortium. The countries chosen based on these criteria were: the Czech Republic, Germany, the UK, Italy and Sweden. To reduce non-respondent bias and to better reflect the general population of women at screening age in each country, we applied quotas matching the distribution of age and education of the general population of each country at the point of survey completion. Quotas per country were calculated on the grounds of three levels of education (low, medium and high) as categorised by the International Standard Classification of Education (ISCED) and of four age groups (40-49 years, 50-59 years, 60-69 years and 70-75 years). We calculated that a sample size of 300 participants per country was required to detect differences in knowledge of $20 \%$ or higher within and between samples. To allow for non-response and ineligibility, Harris eventually drew a sample of 3629 women from the panels.

\section{Survey administration}

In January 2017, Harris Interactive contacted eligible women in each of the five European countries by email. The email provided basic information about the study, the link to the study (with a personalised password) in the nation-specific language of the target population and an offer of a $€ 5$ honorarium on completion of the survey. Up to two reminder emails were sent to non-respondents until the intended sample size was met.

\section{Survey questionnaire and intervention}

The survey study comprised a leaflet intervention and two main questions concerning female cancer risks and screening knowledge, which were asked before and after the intervention. For the question on female cancer risks, women were asked to provide their numerical estimates (open-field response) of how many women out of 1000 in her specific age group will be diagnosed with each of the following four listed female cancers (breast, ovarian, cervical and endometrial cancer) within the next 10 years. The order of cancer types was always randomised. Next, they were asked whether cancer screening such as mammography: (1) comes with benefits (reduction of cancer deaths) but no harms, (2) comes with benefits (reduction of cancer deaths) and harms (eg, overdiagnosis) or (3) helps prevent cancer before it starts. Again, the order of the possible answers was always randomised. After responding to the questions, women were next presented online with the leaflet intervention. Women were not told that they would be later queried on the same questions again and, after opening the leaflet online, were no longer able to return to the initial part of the survey.

The leaflet was developed at early stages together with focus groups of women at target age and was based on the guideline for evidence-based health information of the German Network for Evidence-Based Medicine, ${ }^{18}$ which recommends informing people about the actual risk of a specific disease in question, informing them about potential interventions by using absolute numbers and the same reference class when describing the benefit and harms and setting this benefit-harm information in context with the option of doing nothing if applicable. Accordingly, the leaflet informed women on age-specific risks (45 years, 55 years, 65 years and 75 years) for breast, ovarian, cervical and endometrial cancer in the general population over a period of 10 years; on current approaches of cancer screening-exemplified in detail for mammography screening - and prevention; and on the benefit-harm ratio of populations attending or not attending mammography screening based on current evidence $^{19}$ and exemplified in a facts box, ${ }^{20}{ }^{21}$ which has been shown to improve understanding even in people with low literacy levels. ${ }^{22}$ Women could take as much time as they desired to familiarise themselves with the content of the leaflet. After they finished reading the leaflet by clicking the next button, women were presented with the initial questions again and no longer able to return to the leaflet. The exact wording of the survey and leaflet can be seen in the online supplementary file.

The leaflet was part of a larger study on: (1) women's knowledge about female cancers and cancer screening and (2) their attitude towards a forthcoming epigenetic predictive test on female cancer risks (WID test). Results from the second part of the study, which do not deal with women's knowledge of current risk and clinical practice, go beyond the scope of this article and will be presented elsewhere.

\section{Outcomes}

The primary outcomes were the: (1) proportion of women accurately estimating their risk of four female cancers, (2) proportion of women holding correct assumptions about mammography screening and (3) proportional changes in these estimations and assumptions after exposure to the leaflet. The secondary outcomes were: (1) differences in the proportion of correct judgements between the five European countries, (2) differences in this proportion between women belonging and not belonging to the core age group (50-69 years) of systematic mammography screening and (3) the association between an accurate estimation of breast cancer risk and misconceptions of mammography.

\section{Statistical analysis and data presentation}

The online version of the questionnaire did not allow for item non-response; thus, all 1675 questionnaires were completed in full. Epidemiological data on age-specific 10-year risks for each of the female cancers were derived from the population-based cancer registry database of the Robert Koch Institute (www.krebsdaten.de) in Germany. ${ }^{23}$ Details on the age-specific risks for each of the four female cancers derived from the database can 
Table 1 Actual age-specific risks of developing a certain female cancer within the next 10 years displayed for different age groups and for each of the four female cancers

Numbers of women who will develop cancer within the next 10years...*

\begin{tabular}{lllll}
\hline & $\begin{array}{l}\text { per } \mathbf{1 0 0 0} \text { women aged } \\
\text { 45years }\end{array}$ & $\begin{array}{l}\text { per 1000 women aged } \\
\text { 55years }\end{array}$ & $\begin{array}{l}\text { per 1000 women aged } \\
\text { 65years }\end{array}$ & $\begin{array}{l}\text { per 1000 women aged } \\
\text { 75years }\end{array}$ \\
\hline Breast cancer & 21 & 30 & 35 & 33 \\
Ovarian cancer & 2 & 3 & 4 & 4 \\
Cervical cancer & 2 & 2 & 1 & 1 \\
Endometrial cancer & 2 & 5 & 6 & 6 \\
\hline
\end{tabular}

*All age-specific cancer risks displayed in the table are based on the population-based cancer registration dataset of the German Centre for Cancer Registry Data within the Robert Koch Institute (www.krebsdaten.de), database query, 1 August 2016.

be seen in table 1 . To accommodate for potential country-specific variations in female cancer risks, women's responses to the knowledge questions on female cancer risks were rated correctly within a $\pm 50 \%$ margin of error. For instance, if the risk of a 55-year-old woman developing breast cancer within the next 10 years was 30 out of 1000 women, estimates between 15 and 45 were considered correct. Estimates above the upper bound of the $50 \%$ margin of error were rated as 'overestimations' and those below the lower bound of the $50 \%$ margin as 'underestimations'. Women's responses to the question concerning their knowledge of mammography screening were rated correct if they chose the option stating that the screening comes with benefits (reduction of cancer deaths) and harms (eg, overdiagnosis), as suggested by scientific evidence. ${ }^{79}$ Because a personal history of female cancer may have influenced women's estimates of their personal female cancer risk, we analysed all data including and excluding the 129 women who reported a personal history of female cancer or were unsure about their past diagnosis. These analyses showed no effect on the outcome measures reported here, which is why we present all sample data in full.

To define the core age group, we decided on women eligible for mammography screening for breast cancer (50-69 years) because this is an implemented, systematic population-based screening programme in each of the five European countries, for which women in these countries receive an invitation letter every second year supplemented with information material.

All results are provided as absolute frequencies with $95 \%$ CIs. The non-parametric Wilcoxon test was used in order to perform within-group analyses of data collected from women comprising correct versus incorrect estimates of their perceived risk of developing breast cancer and also the variance in their misconceptions of mammography screening. All data were stored and analysed using IBM SPSS Statistics V.24.

\section{Patient involvement}

Patients were not involved in the design or conduct of the study. There is no plan to disseminate the results to study participants.

\section{Data sharing}

The full dataset is available to researchers via an application to the FORECEE (4C) consortium group.

\section{Role of funding sources}

The corresponding author had full access to all the data in the study and had final responsibility for the decision to submit for publication.

\section{RESULTS}

\section{Sample description}

Of 3629 women invited, 848 did not respond, 197 were not eligible (duplicate listing, other strata than originally coded) and 492 entered the survey after respective quotas were filled. Of the 2092 who responded, 417 did not finish the survey, resulting in 1675 completed surveys. Using the American Association for Public Opinion Research response rate calculator, which incorporates a default method for estimating $e$ (estimated proportion of cases of unknown eligibility that is eligible), the survey yielded a response rate of $61.4 \%(1675 /[1675+417+e(848)])$ and a cooperation rate of $80.1 \%(1675 /[1675+417])$.

Of the 1675 surveys collected in total, 356 were completed in the Czech Republic, 335 in Germany, 323 in the UK, 338 in Italy and 323 in Sweden. Across countries, the distribution of age groups was: 40-49 (29.6\%) years, 50-59 $(29.3 \%)$ years, 60-69 $(29.5 \%)$ years and 70-75 (11.7\%) and the distribution of educational levels was: low $(27.8 \%)$, medium (48.8\%) and high $(23.5 \%)$. One hundred and four women reported a personal history of female cancer in the past and 25 were not sure if their diagnosis concerned a female cancer. Table 2 provides country-specific details on these characteristics. Note that based on the official distribution of ISCED levels for each country, the proportion of respondents with low, medium and high levels of education differed across the five national samples in our study. Additional details on the match between the joint distribution of age and education within each of the national samples and the joint distribution of these two characteristics in each of the respective national populations are given in the online supplementary table 1). 
Table 2 Characteristics of study sample

\begin{tabular}{|c|c|c|c|c|c|c|}
\hline \multicolumn{7}{|c|}{ Number of participants (\%) } \\
\hline & $\begin{array}{l}\text { All countries } \\
(n=1675)\end{array}$ & $\begin{array}{l}\text { Czech Republic } \\
(n=356)\end{array}$ & $\begin{array}{l}\text { Germany } \\
(n=335)\end{array}$ & $\begin{array}{l}\text { UK } \\
(n=323)\end{array}$ & $\begin{array}{l}\text { Italy } \\
(n=338)\end{array}$ & $\begin{array}{l}\text { Sweden } \\
(n=323)\end{array}$ \\
\hline \multicolumn{7}{|c|}{ Age group (years) } \\
\hline $40-49$ & $495(29.6)$ & $100(28.1)$ & $96(28.7)$ & $101(31.3)$ & $102(30.2)$ & $96(29.7)$ \\
\hline $50-59$ & $490(29.3)$ & $90(25.3)$ & $109(32.5)$ & $101(31.3)$ & $96(28.4)$ & $94(29.1)$ \\
\hline \multicolumn{7}{|c|}{ Education (ISCED) } \\
\hline High & $393(23.5)$ & $52(14.6)$ & $65(19.4)$ & $116(35.9)$ & $43(12.7)$ & $117(36.2)$ \\
\hline Medium & $817(48.8)$ & 256 (71.9) & 207 (61.8) & $111(34.4)$ & $112(33.1)$ & $131(40.6)$ \\
\hline Low & 465 (27.8) & $48(13.5)$ & $63(18.8)$ & $96(29.7)$ & $183(54.1)$ & 75 (23.2) \\
\hline No & $1546(92.3)$ & $330(92.7)$ & $311(92.8)$ & $300(92.9)$ & $311(92.0)$ & 294 (91.0) \\
\hline
\end{tabular}

ISCED, International Standard Classification of Education.

\section{Women's knowledge of their age-specific cancer risk for female cancers}

Among all women, 23.3\% (range country-specific correct responses: : $18.1 \%-29.3 \%$ ) provided a correct estimate of their age-specific risk for breast cancer within the next 10 years, $15.6 \%$ (range: $11.1 \%-23.6 \%$ ) for ovarian cancer, $6.8 \%$ (range: $3.4 \%-11.9 \%$ ) for cervical cancer and $12.7 \%$ (range: $9.6 \%-19.4 \%$ ) for endometrial cancer. A minority of women underestimated their age-specific cancer risks: $17.5 \%$ for breast cancer, $2.8 \%$ for ovarian cancer, $1.4 \%$ for cervical cancer and $5.0 \%$ for endometrial cancer. Less than $1.7 \%$ considered their cancer risk for any of the four female cancers to be zero. The majority of women overestimated their age-specific risks: $59.2 \%$ for breast cancer, $81.6 \%$ for ovarian cancer, $91.8 \%$ for cervical cancer and $82.3 \%$ for endometrial cancer. The magnitude of overestimation across all women was 7-fold (median ${ }_{\text {overestimations: }}$ : 200.0, range overestimations $_{35.0-950.0)}$ for the age-specific risk for breast cancer, 16-fold (median: 50.0, range: 4.0-900.0) for ovarian cancer, 33-fold (median: 50.0, range: 3.0-999.0) for cervical cancer and 11-fold (median: 50.0, range: 4.0-900.0) for endometrial cancer.

The highest proportion of correct estimates and the smallest proportion of overestimations of the age-specific risk for each of these cancers were observed among women in Germany, and the lowest proportion of correct estimates and highest proportion of overestimations among women in the UK (all country-specific estimates, table 3).

\section{Women's knowledge of mammography screening}

Overall, $26.5 \%$ of women correctly knew that cancer screening such as mammography can result in both benefits (eg, cancer-specific mortality reduction) and harms (eg, overdiagnosis), with the highest proportion of correct responses observed among women in Germany $(43.3 \%)$ and the lowest proportion among women in Italy (13.3\%) (table 4). Among women in the Czech Republic, Italy and Sweden, the highest proportion incorrectly believed that mammography screening prevents breast cancer: $59.7 \%$, $50.9 \%$ and $42.7 \%$, respectively. For women in the UK, there was no clear difference in the proportion of women holding the correct or either of the two incorrect beliefs (table 4). Women who demonstrated accurate knowledge of their breast cancer risks were less likely to believe that mammography screening would prevent cancer than women who demonstrated incorrect knowledge $(z=-5.46, \mathrm{p}<0.001$, $\mathrm{r}=0.24)$.

\section{Breast cancer and screening knowledge of women in the core age group}

Within each country, women in the core age group for mammography screening (50-69 years) displayed no better knowledge of their breast cancer risk than did women outside this group: $22.2 \%$ (95\% CI 19.6 to 24.9 ) and $23.3 \%$ (21.3-25.4), respectively (table 3). Also, they showed no better understanding of the fact that mammography can result in both benefits and harms than did women outside the core age group for mammography: only $26.9 \%$ (95\% CI 24.2 to 29.8 ) and $26.5 \%$ (24.4-28.7), respectively, knew that mammography screening has both benefits and harms (table 4).

\section{Effect of an evidence-based patient leaflet on women's knowledge of cancer risks and cancer screening}

After being presented with the intervention leaflet, the proportion of women correctly estimating their cancer-specific risks for each of the four female cancers notably increased: $30.7 \%, 37.1 \%, 27.0 \%$ and $36.7 \%$ for breast, ovarian, cervical and endometrial cancer, respectively (table 3). 
อ อ

ผ

용ㅇ 우

ก)

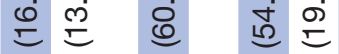

กิ่

要

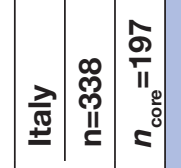

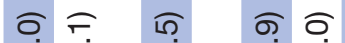

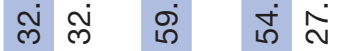

아 우우

m ए

ิㅗ $\stackrel{\infty}{=}$ 过

๙ั่

ฮิ ศิ จุ ตุ

กั

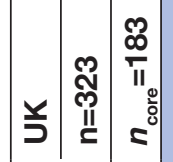

아 우

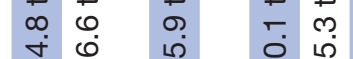

ᄃ 을

๙

ซ สุ

ले ठิ ति ญु

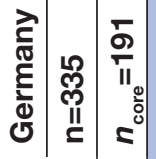

웅

จ T.

高全过

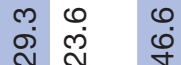

$+4$

Ni

क) 6

กิ่

ซ ल

ผึ่ ปิ

아 우 우

Uิ

总

है

के 0 II $=$

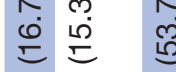

ฉิ จे

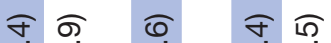

ผู่ ปั

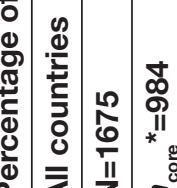

유 우 우

m

m N N

กิ ลั
ฮิ สุ อิ

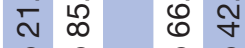

우 우 우

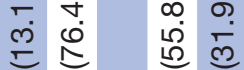

담

$\widehat{0} \widehat{0}$

స.

둥ำ

@ं

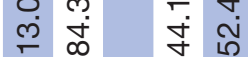

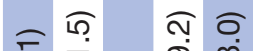

เก

운

穴

$r$ N

$\mp \infty$

กั่

+2 웅

ग.

过

ก.

กี่ ช่

ธุ อ สุ

$\stackrel{\infty}{\sim}$

षे

우 우

$\ulcorner 0$ 寸

คำ

造

0 ก

वे

लํ

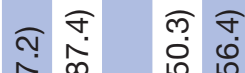

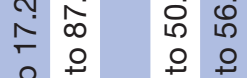

유 +5

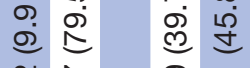

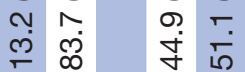

ซ $\widehat{\sim}$ ด

ก

+2 웅

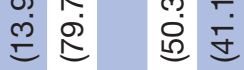

0.0

เं

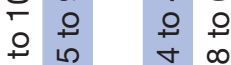

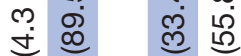

œ

ले

สุ่

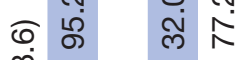

$\infty$ 요요

$+m$ m

๑

( 60 \% 0

เั ภู่

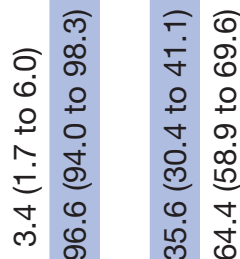

๙ิ

요

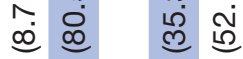

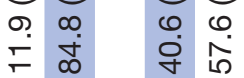

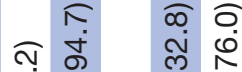

के

+

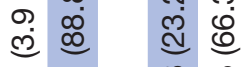

ง

๑ ภู่ ลั

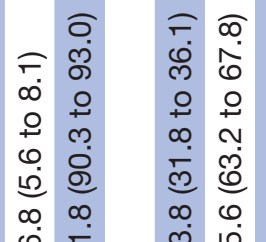

$\infty$

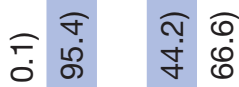

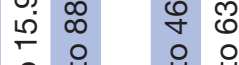

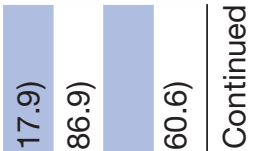

+ 의

둔

0 O

ஸ் ம்

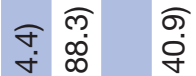

ㄷㅇㅇㅛ 웅

ㄴ @

กิ

ल)

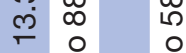

$+\stackrel{0}{0}+0$

它家守

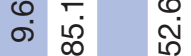

$\widehat{F} \widehat{F}$

㐫

$\circ$ 웅

N N

$\stackrel{10}{=}$

ๆ.

ब ल

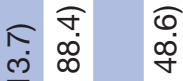

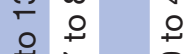

กิ

$\leftarrow \infty$

유 官

क़

요 우

ז

त.

ำ

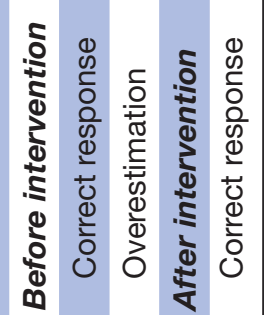

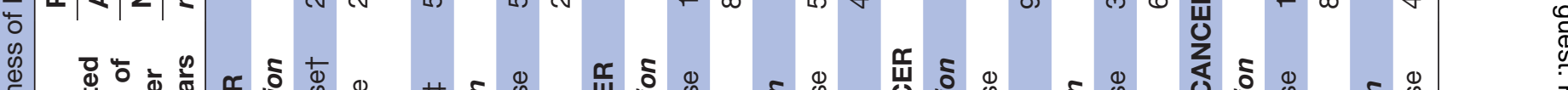


The proportion of women who overestimated their cancer risks declined by $38.7 \%, 38.1 \%, 26.2 \%$ and $39.5 \%$ for breast, ovarian, cervical and endometrial cancer, respectively (table 3). Likewise, the magnitude of overestimations decreased across countries for breast cancer from 7-fold to 3-fold (median $n_{\text {overstimation: }}$ : 100.0, range : 33.0-900.0), for ovarian cancer from 16-fold to 6-fold (median: 20.0, range: 4.0-900.0), for cervical cancer from 33-fold to 6-fold (median: 10.0, range overestimations :3.0-950.0) and for endometrial cancer from 11-fold to 4-fold (median: 21.0, range: 4.0-950.0) (figure 1).

Furthermore, women's awareness that mammography screening can result in both benefits and harms significantly increased by $17.0 \%-35.3 \%$ across countries (table 4). At the same time, the proportion of women holding one of the two incorrect beliefs concerning mammography screening decreased across countries by $4.9 \%-20.8 \%$ (table 4 ).

Although improvements in knowledge about female cancer risks and mammography were significant within each national sample, the actual extent of improvements varied across countries, with the largest improvements in estimates of the four female cancer risks observed in the UK $(32.2 \%-43.0 \%)$ and Sweden $(31.9 \%-44.3 \%)$ and the smallest in the Czech Republic (21.6\%-33.3\%) and Italy (21.3\%-31.1\%) (table 3). Women from the UK further showed the largest improvement in a correct understanding of mammography screening (35.3\%), whereas that improvement in the other four countries did not significantly differ (Sweden: $17.0 \%$, Italy: $20.1 \%$, Germany: 21.2\% and Czech Republic: 21.9\%) (table 4).

\section{DISCUSSION}

In our survey of 1675 women in five European countries, $59.2 \%-91.8 \%$ overestimated their age-specific risks for four female cancers by 7 -fold to 33 -fold. Over $70 \%$ did not know that mammography screening has both benefits and harms but instead believed that it has only benefits or can even prevent breast cancer. Those eligible for population-based mammography screening programmes and regularly invited to participate by health authorities demonstrated no better understanding of these facts. Women with incorrect knowledge of their breast cancer risk were particularly likely to believe that mammography screening can prevent the onset of breast cancer.

Where do these misunderstandings originate? Although we did not actively investigate potential reasons, findings from other studies ${ }^{1524}$ suggest that insufficient communication of risks by health-specific sources can be influential. Few leaflets, letters of invitation to screenings and health websites use absolute statistics to explain the actual risk of cancer and the potential benefits and harms of screening. ${ }^{24-28}$ Instead, they often use relative statistics, lifetime incidences, 5-year survival rates or no numbers at all, all of which contribute to women seriously overestimating their own cancer risk and the benefit of screening. ${ }^{29-33}$ Also, European health information on mammography 


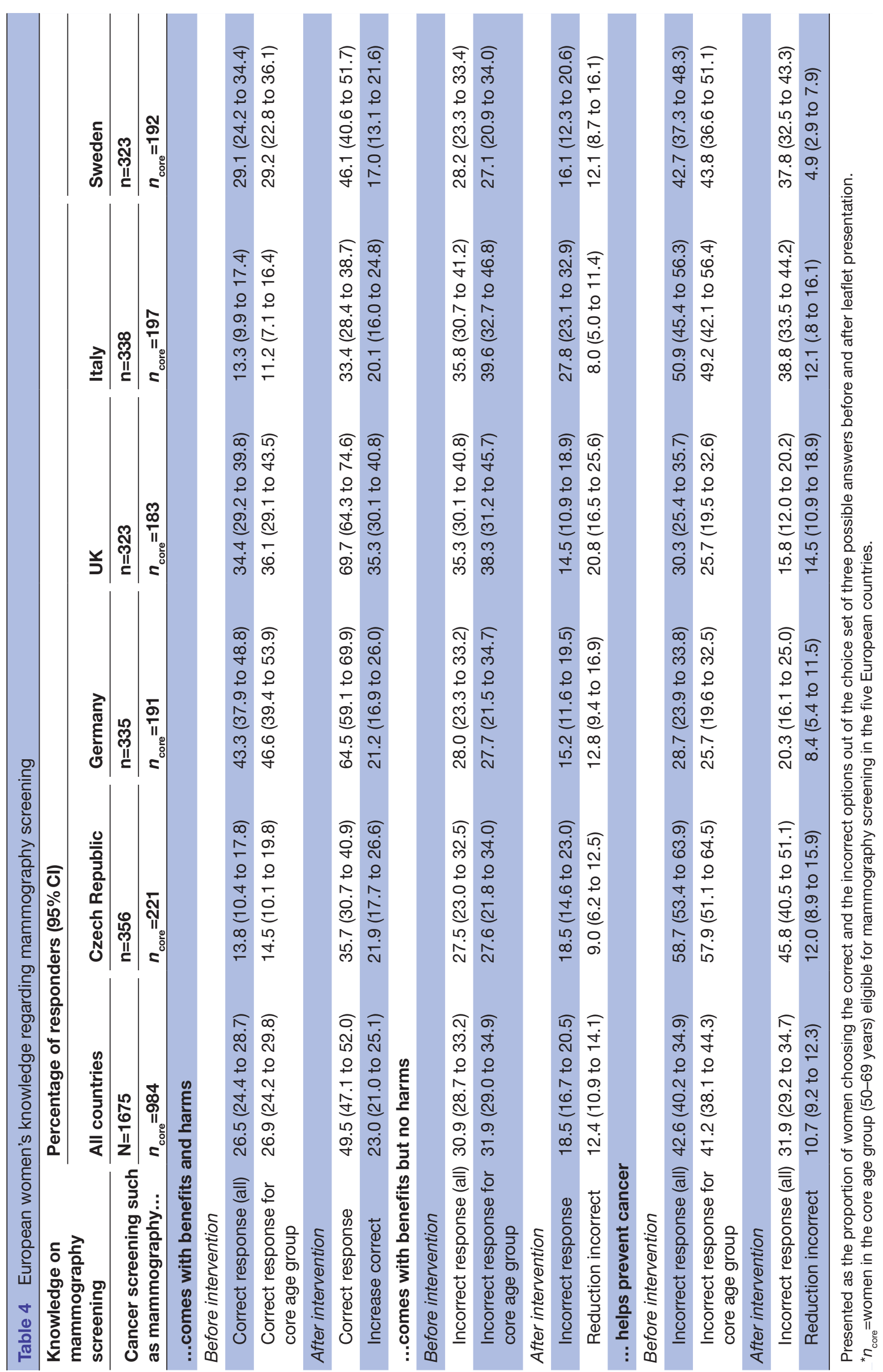



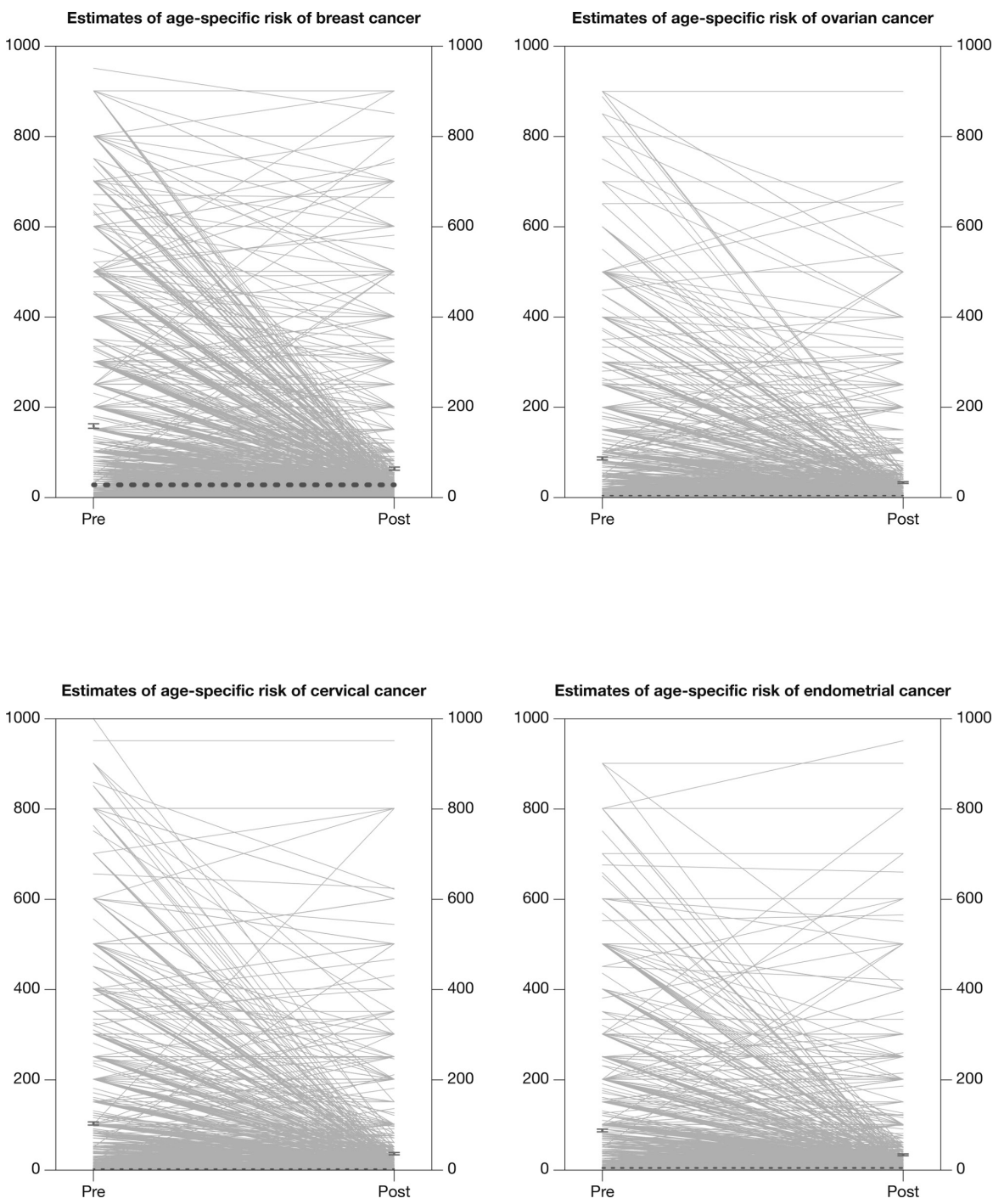

Figure 1 European women's estimates of their age-specific risks of breast, ovarian, cervical and endometrial cancer before and after reading the evidence-based leaflet with standard error (marked in dark grey). The dotted line marks the accepted area of correct estimates for each of the cancer risks.

cancer screening is often unbalanced and has been criticised by health authorities (eg, National Board of Health and Welfare in Sweden ${ }^{34}$ and Federal Joint Committee in Germany ${ }^{35}$ ) for insufficiently informing the public. As a consequence, the Federal Joint Committee in Germany passed a resolution in 2015 to standardise patient information on mammography screening by basing it on the guidelines for evidence-based health information; all women invited to the programme have since been given this new information. ${ }^{35}$ For other screening programmes, nationwide standardised, evidence-based information for women does not exist. Delivering adequate information is thus mainly left to gynaecologists offering screening for female cancers. However, considering that past studies found physicians to be susceptible to framing effects created by using relative as opposed to absolute risk reduction formats, ${ }^{36-40}$ have difficulty calculating the positive predictive value of tests ${ }^{41-44}$ or misunderstand screening statistics, ${ }^{45}$ it remains an open question as to whether women will receive the requisite information needed to make an informed choice.

From a positive point of view, our findings demonstrate that the provision of balanced, evidence-based health information substantially improves women's knowledge of their age-specific cancer risks and their understanding of mammography screening: overestimations of their own cancer risk declined by 26.2-39.5 percentage points and the number of women who consequently knew that mammography can result in benefits and harms doubled. Taking into account the level of education (as measured by the ISCED), we observed significant improvements-although to a different extent-across all questions among women with a low, medium and high ISCED rating, suggesting that regardless of education level, women will profit from balanced health information (online supplementary table 2 ), and even though the national samples in our study differed in the distribution of education levels, reflecting real differences in the distribution of this characteristic 
in the respective country-specific base population, we observed no relevant systematic differences in knowledge of cancer risk and understanding of mammography before intervention or systematic differences in improvements of that knowledge and understanding after intervention.

\section{Limitations}

One needs to be mindful of some limitations when considering our study's findings. First, we chose a $\pm 50 \%$ margin of error for the age-specific cancer risks as a proxy denoting a correct estimate. Since the actual risk of breast cancer is approximately 10 times higher than the risks of the other three cancer types, the rule applied made it more likely that women's responses were rated correct for their estimated breast cancer risk than for the other three cancer types. Second, our study did not assess whether the degree of overestimating one's cancer risk or the improved knowledge observed after the intervention actually translate into any behavioural changes, for example, lower or higher participation rates in screening. Other studies from the USA ${ }^{47}$ found, however, that overestimating one's own cancer risk is associated with largely overestimating the mortality reduction of cancer screening, which in turn has been found in further studies to be associated with higher participation rates. ${ }^{17} 48$ Third, the cross-sectional design of the study prevented us from assessing durability of improvements in knowledge. We thus are not able to judge whether women maintain over a longer run the improvements in knowledge we found in our study. Fourth, we cannot rule out the existence of non-respondents' bias. Although we achieved a reasonable response rate and stratified the sample to match women's characteristics for age and education in our sample to the general population at survey completion, we cannot exclude the likelihood that women with higher cancer risks due to close family history or a greater interest in the topic of cancer and screening were more likely to respond to our survey, which might have influenced our results and limit the generalisability of our results. However, analyses excluding women who reported a personal history of female cancer in our study did not change any of the results reported here. Fifth, we can only speculate why women from different European countries substantially varied in their knowledge on female cancer risks and mammography in the first place. A comparison of country-specific health information on mammography provided to women in these five European showed a considerable variance in standardisation (ie, women within the same country receive/d not receive identical information, information is given/not given on i. age-specific cancer prevalence, ii.benefits and harms of screening and on iii. positive/negative predictive value of test). To what extent these differences in health information explain our findings needs to be studied in greater detail in future studies.

\section{CONCLUSION}

Despite these limitations, our study suggests that a large proportion of women in five European countries are highly uninformed about their cancer risks and mammography screening. In these cases, informed decision making about cancer screening is not possible. From a definitive perspective, the present study shows that a correctly perceived cancer risk is positively associated with women's expectations of cancer screening and that evidence-based information has the potential to improve women's understanding of their cancer risks and screening facts. These findings should encourage health authorities to continue their endeavours to implement evidence-based, standardised cancer health information.

\section{Author affiliations}

${ }^{1}$ Center for Adaptive Rationality, Max Planck Institute for Human Development, Berlin, Germany

${ }^{2}$ Harding Center for Risk Literacy, Max Planck Institute for Human Development, Berlin, Germany

${ }^{3}$ Department of Women's Cancer, University College London, London, UK ${ }^{4}$ Department of Obstetrics and Gynecology, Charles University Prague (Czech Republic), Prague, UK

${ }^{5}$ Department of Laboratory Medicine, Karolinska Institutet, Stockholm, Sweden ${ }^{6}$ Laboratory Karolinska University Hospital, Karolinska University, Stockholm, Sweden

${ }^{7}$ Unit of Gynecology, Humanitas Research Hospital, Milan, Italy

${ }^{8}$ Unit of Preventive Gynecology, European Institute of Oncology, Milan, Italy

Acknowledgements We would like to thank the FORECEE consortium members for their insightful contributions to discussions of the survey results during FORECEE meetings and Rona Unrau and Dr Julie Bennett for their help in editing the manuscript.

Collaborators FORECEE (4C) consortium members: Prof. Joakim Dillner, Dr. Michal Zikan, Dr. Line Bjorge, Prof. Nicoletta Colombo, Dr. Richard Hadwin, Prof. Nadia Harbeck, Prof. Frank Dudbridge, Prof. Ewout Steyerberg, Prof. Inez de Beaufort, Prof. Uwe Siebert, Dr. Gaby Sroczynski, Dr. Andreas Leimbach, Dr. Tobias Paprotka, Ms. Allison Jones

Contributors Study concept and design: OW and FGR; acquisition of data: all authors; analysis of data: OW and FGR; interpretation of data: all authors; drafting of the manuscript: OW; critical revision of the manuscript for important intellectual content: all authors; statistical expertise: OW and FGR; study supervision: OW, MW and FGR. Final approval of the submitted version of the manuscript: all authors.

Funding The work was funded by the European Union's Horizon 2020 research and innovation project: Female cancer prediction using cervical omics to individualise screening and prevention (FORECEE; grant agreement number: 634570; https://forecee.eu/). MW's contributions were undertaken at University College London Hospitals/University College London, which received a proportion of its funding from the Department of Health NIHR Biomedical Research Centres funding scheme. Guarantor of the manuscript: $\mathrm{OW}$.

Disclaimer The funding organisations had no role in the design, conduct, collection, analysis and interpretation of the data and no role in the preparation, review or approval of the manuscript.

Competing interests None declared.

Patient consent Not required.

Ethics approval The study was approved by the Institutional Ethics Board of the Max Planck Institute for Human Development, Berlin (Germany).

Provenance and peer review Not commissioned; externally peer reviewed.

Data sharing statement All authors had full access to all the data in the study and take responsibility for the integrity of the data and the accuracy of the data analysis.

Open access This is an open access article distributed in accordance with the Creative Commons Attribution Non Commercial (CC BY-NC 4.0) license, which permits others to distribute, remix, adapt, build upon this work non-commercially, and license their derivative works on different terms, provided the original work is properly cited, appropriate credit is given, any changes made indicated, and the use is non-commercial. See: http:// creativecommons.org/licenses/by-nc/4.0/. 


\section{REFERENCES}

1. Etzioni R, Penson DF, Legler JM, et al. Overdiagnosis due to prostate-specific antigen screening: lessons from U.S. prostate cancer incidence trends. J Nat/ Cancer Inst 2002;94:981-90.

2. Welch HG, Black WC. Overdiagnosis in cancer. J Natl Cancer Inst 2010;102:605-13.

3. Marcus PM, Prorok PC, Miller AB, et al. Conceptualizing overdiagnosis in cancer screening. J Natl Cancer Inst 2015;107.djv014.

4. Buys SS, Partridge E, Black A, et al. Effect of screening on ovarian cancer mortality: the Prostate, Lung, Colorectal and Ovarian (PLCO) Cancer Screening Randomized Controlled Trial. JAMA 2011;305:2295-303.

5. Schröder FH, Hugosson J, Roobol MJ, et al. Screening and prostate cancer mortality: results of the European Randomised Study of Screening for Prostate Cancer (ERSPC) at 13 years of follow-up. The Lancet 2014;384:2027-35.

6. Atkin WS, Edwards R, Kralj-Hans I, et al. Once-only flexible sigmoidoscopy screening in prevention of colorectal cancer: a multicentre randomised controlled trial. Lancet 2010;375:1624-33.

7. Autier P, Boniol M, Koechlin A, et al. Effectiveness of and overdiagnosis from mammography screening in the Netherlands: population based study. BMJ 2017;359:j5224.

8. Welch HG, Prorok PC, O'Malley AJ, et al. Breast-cancer tumor size, overdiagnosis, and mammography screening effectiveness. $N$ Engl J Med 2016;375:1438-47.

9. Woloshin S, Schwartz LM. Numbers needed to decide. J Nat/ Cancer Inst 2009;101:1163-5.

10. Wegwarth O, Gigerenzer G. Improving evidence-based practices through health literacy--reply. JAMA Intern Med 2014;174:1413-4.

11. Shieh $Y$, Eklund M, Madlensky L, et al. Breast cancer screening in the precision medicine era: Risk-based screening in a population-based trial. J Natl Cancer Inst 2017;109:djw290.

12. Jacobs IJ, Menon U, Ryan A, et al. Ovarian cancer screening and mortality in the UK Collaborative Trial of Ovarian Cancer Screening (UKCTOCS): a randomised controlled trial. Lancet 2016;387:945-56.

13. Moss HA, Berchuck A, Neely ML, et al. Estimating costeffectiveness of a multimodal ovarian cancer screening program in the United States: secondary analysis of the UK Collaborative Trial of Ovarian Cancer Screening (UKCTOCS). JAMA Oncology 2017. 4:190-195.

14. Andrae B, Kemetli L, Sparén P, et al. Screening-preventable cervical cancer risks: evidence from a nationwide audit in Sweden. J Natl Cancer Inst 2008;100:622-9.

15. Gigerenzer G, Mata J, Frank R. Public knowledge of benefits of breast and prostate cancer screening in Europe. J Natl Cancer Inst 2009;101:1216-20.

16. Wegwarth O, Gigerenzer G. Less is more: Overdiagnosis and overtreatment: evaluation of what physicians tell their patients about screening harms. JAMA Intern Med 2013;173:2086-7.

17. Dierks ML, Schmacke N. Mammografie-Screening und informierte Entscheidung: mehr Fragen als Antworten [Mammography screening and informed consent: more questions than answers]. In: Boecker J, Braun B, Meierjuergen R, eds. Gesundheitsmonitor 2014: Buergerorientierung im Gesundheitswesen Bertelsmann Stiftung, 2014:55-91.

18. Steckelberg A, Berger B, Köpke S, et al. Kriterien für evidenzbasierte Patienteninformationen. Zeitschrift für ärztliche Fortbildung und Qualität im Gesundheitswese 2005;99:343-51.

19. Gøtzsche PC, Jørgensen KJ. Cochrane Breast Cancer Group. Screening for breast cancer with mammography. Cochrane Database Syst Rev 2013;156.

20. Schwartz LM, Woloshin S, Welch HG. The drug facts box: providing consumers with simple tabular data on drug benefit and harm. Med Decis Making 2007;27:655-62.

21. McDowell M, Rebitschek FG, Gigerenzer G, et al. A simple tool for communicating the benefits and harms of health interventions: A guide for creating a fact box. MDM Policy Pract 2016;1:2381468316665365.

22. Schwartz LM. Using a drug facts box to communicate drug benefits and harms. Ann Intern Med 2009;150:516-27.

23. Kaatsch P, Spix C, Katalinic A, et al. Gesundheitsbereichterstattung des Bundes: Krebs in Deutschland 2011/2012 [Public health reports of the goverment: cancer in Germany 2011/2012]. Berlin: Robert Koch Institute 2015.
24. Wegwarth O, Kurzenhäuser-Carstens S, Gigerenzer G. Overcoming the knowledge-behavior gap: The effect of evidence-based HPV vaccination leaflets on understanding, intention, and actual vaccination decision. Vaccine 2014;32:1388-93.

25. Bodemer N, Müller SM, Okan Y, et al. Do the media provide transparent health information? A cross-cultural comparison of public information about the HPV vaccine. Vaccine 2012;30:3747-56.

26. Neumeyer-Gromen A, Bodemer N, Müller SM, et al. Ermöglichen Medienberichte und Broschüren informierte Entscheidungen zur Gebärmutterhalskrebsprävention? [Do media reports and public brochures facilitate informed decision making about cervical cancer prevention?]. Bundesgesundheitsblatt 2011;54:1197-210.

27. Slaytor EK, Ward JE. How risks of breast cancer and benefits of screening are communicated to women: analysis of 58 pamphlets. BMJ 1998;317:263-4.

28. Kurzenhäuser S. Welche Informationen vermitteln deutsche Gesundheitsbroschüren über die Screening-Mammographie? [What information do German health brochures provide on mammography screening?]. Zeitschrift für ärztliche Fortbildung und Qualitätssicherung 2003;97:53-7.

29. Perneger TV, Agoritsas T. Doctors and patients' susceptibility to framing bias: a randomized trial. J Gen Intern Med 2011;26:1411-7.

30. Malenka DJ, Baron JA, Johansen S, et al. The framing effect of relative and absolute risk. J Gen Intern Med 1993;8:543-8.

31. Gigerenzer G, Gaissmaier W, Kurz-Milcke E, et al. Helping doctors and patients make sense of health statistics. Psychol Sci Public Interest 2007;8:53-96.

32. Woloshin S, Schwartz LM. How a charity oversells mammography. BMJ 2012;345:e5132.

33. Welch HG, Schwartz LM, Woloshin S. Are increasing 5-year survival rates evidence of success against cancer? JAMA 2000;283:2975-8.

34. The Swedish National Board of Health and Welfare. Screening for breast cancer - Recommendation and basis for assessment. Socialstyre/sen online 2017 http://www.socialstyrelsen.se/SiteCollecti onDocuments/screening-brostcancer-rekommendation.pdf.

35. Federal Joint Committee in Germany. Mammographie-Screening Frauen erhalten neue Entscheidungshilfe. https://www.g-ba.de/ institution/presse/pressemitteilungen/712/2017.

36. McGettigan P, Sly K, O'Connell D, et al. The effects of information framing on the practices of physicians. J Gen Intern Med 1999;14:633-42.

37. Moxey A, O'Connell D, McGettigan P, et al. Describing treatment effects to patients: How they are expressed makes a difference. Journal of General Internal Medicine 2003;18:948-59.

38. Jain BP. Number needed to treat and relative risk reduction. Ann Intern Med 1998;128:72-3.

39. Sethuraman R, Cole C, Jain D. Analyzing the effect of information format and task on cutoff search strategies. Journal of Consumer Psychology 1994;3:103-36.

40. Covey J. A meta-analysis of the effects of presenting treatment benefits in different formats. Med Decis Making 2007;27:638-54.

41. Eddy DM. Probabilistic reasoning in clinical medicine: Problems and opportunities. In: Kahneman D, Slovic P, Tversky A, eds. Judgment under uncertainty: Heuristics and biases. Cambridge: Cambridge University Press, 1982:249-67.

42. Casscells W, Schoenberger A, Graboys TB. Interpretation by physicians of clinical laboratory results. $N$ Engl J Med 1978;299:999-1001.

43. Bramwell R, West $H$, Salmon P. Health professionals' and service users' interpretation of screening test results: experimental study. BMJ 2006;333:284-6.

44. Hoffrage U, Gigerenzer G. Using natural frequencies to improve diagnostic inferences. Acad Med 1998;73:538-40.

45. Wegwarth O, Gaissmaier W, Gigerenzer G. Deceiving numbers: survival rates and their impact on doctors' risk communication. Med Decis Making 2011;31:386-94.

46. Wegwarth O, Schwartz LM, Woloshin S, et al. Do physicians understand cancer screening statistics? A national survey of primary care physicians in the United States. Ann Intern Med 2012;156:340-9.

47. Black WC, Nease RF, Tosteson AN. Perceptions of breast cancer risk and screening effectiveness in women younger than 50 years of age. J Natl Cancer Inst 1995;87:720-31.

48. Miller AM, Champion VL. Attitudes about breast cancer and mammography: racial, income, and educational differences. Women Health 1997;26:41-63. 